\title{
MicroSKED
}

\author{
F. E. BUTLER \\ Bettendorf, Iowa 52272
}

\begin{abstract}
MicroSKED has transferred the assets of SKED to a microprocessor. Designed around the 6502 microprocessor, MicroSKED contains an editor, compiler, and run-time system. The basic system has 512 words of user memory, 124 inputs, 4 outputs, a time-of-day clock, a keyboard, and a display. The projected cost of the system is $\$ 300$. The system may be expanded. Differences between SKED and MicroSKED are examined.
\end{abstract}

At the second annual meeting of the National Conference on the Use of On-Line Computers in Psychology, Norman (1973) expressed a preposterous idea: A computer would soon be built that would fit within a briefcase. At that time, most microprocessors were still on the design engineers' drawing boards.

In the past 15 years, the price and size of computer installations have decreased at least two orders of magnitude. The PDP- $8^{1}$ was introduced in 1965 at a cost of $\$ 28,000$. The better portion of a room was required to house the computer. In 1973, a system that could fit on a table top could be obtained for $\$ 4,800$ (Snapper, 1974); In1980, there are several microcomputers that are no bigger than a textbook, and they cost less than $\$ 300$. I attended the Sixth National Conference on the Use of On-Line Computers in Psychology with a $22-\mathrm{kg}$ $46 \times 30 \times 8 \mathrm{~cm}$ briefcase. The system contained a cassette recorder, a Teletype interface, a timer, a monitor, $1 \mathrm{~K}$ of random-access memory (RAM), a keyboard, a display, and 15 input-output (I/O) lines. It was heavy and awkward. The major problem was that all programs were written in machine language.

Sof tware has been the rate-limiting step in bringing the electronic advancements into the psychology laboratory. The software that has been developed for the psychologist has either been written for a specific application or has required a substantial amount of time for development.

Whatever software is chosen, it should be versatile, easy to learn, and concise. The expense of a system is always an important consideration. A language that meets the above requirements is SKED. ${ }^{2}$ SKED has been used for diverse experiments (Snapper, 1973). The system can be taught to undergraduates within $4 \mathrm{~h}$ (Butler \& Grisham, 1977).

SKED has been used for many years (Snapper, Knapp, Kushner, \& Kadden, Note 1) and has undergone revisions (Elsmore, 1977; Lewis \& Elsmore, 1973; Snapper, 1973, 1974, 1975; Walker \& Snapper, 1971; Snapper, Stephens, Cobez, \& Van Haaren, Note 2). SKED is the least expensive minicomputer language of those reviewed by Wood, Sette, and Weiss (1975).

Many authors have expounded the virtues of state notation, which is the basis of the SKED language (Snapper, 1973; Snapper \& Kadden, 1973; Stephens \& Van Haaren, 1977; Walker \& Snapper, 1971; Snapper et al., Note 1). State notation describes sequential events (states). One and only one state may be active at any one time. A transition to another state occurs whenever the required amount of a measurable event is satisfied. Time and responses are the events that are measured. At the time of the transition, other changes may occur: Recording counters may be incremented; variables may be defined or changed; stimuli may be presented or removed; analog signals may be measured or generated; computations may occur; data may be stored; and decisions may be made. Although it is theoretically possible to describe any experiment with one collection of states, the number of states may be very great. The use of a number of collections of states (state sets), with intercommunication between the state sets, geometrically increases the power of state notation. The intercommunication between state sets also makes state notation concise. The communication occurs at the time of transition through the use of $Z$-pulses. This increases the events, which may cause a transition, to three (time, response, and $Z$-pulse).

\section{REDUCING SKED}

The impetus for SKED was to create an inexpensive computer system for psychologists (Snapper, 1974). Although SKED is an inexpensive minicomputer system, it has not taken advantage of the price reduction afforded by microcomputers.

MicroSKED has been written to maximize the advantages offered by SKED and to minimize the size, weight, cost, and power requirements of SKED. Certain tradeoffs must occur when the software, designed for a 12-bit computer, is transferred to an 8-bit computer. After 8 years of experience with SKED in undergraduate and graduate research, my primary concern was to maximize the efficiency of MicroSKED while minimizing limitations.

The basic SKED system can control 10 independent boxes; MicroSKED controls 1 box. This restriction is 
not as severe as it appears, due to the price reduction of MicroSKED.

Theoretically, SKED allows a maximum of 4,095 state sets and a maximum of 4,095 states in any 1 state set. But I have never seen a study using 50 states or state sets. Therefore, a maximum of 127 states/state set and 127 state sets appears to be reasonable for MicroSKED.

A maximum count of 4,095 responses of Z-pulses can be used in SKED to cause a transition. A count of 255 is too restrictive, so a maximum count of 65,535 may be used in MicroSKED to cause a transition.

If an individual can afford the cost, SKED allows a maximun of 4,095 different responses; MicroSKED allows a maximum of 124 . SKED allows responses to be simulated through the keyboard. MicroSKED does not allow simulated responses, but it does allow 60 different responses to be made via the keyboard.

Input events can be gated with a probability generator. SKED allows increments of .1\%, while MicroSKED is limited to $1 \%$.

Recording counters in SKED may count up to 4,095 events. The counters in MicroSKED presently count up to 65,535 events. SKED has a provision for doubleprecision recording counters, but MicroSKED has no such provision.

SKED has a two-pass compiler. MicroSKED has a one-pass compiler that requires additional data to be entered by hand. MicroSKED requires that all responses be entered first, all time expressions be entered next, and all Z-pulses be entered last. SKED does not have this restriction.

Finally, the minimal cost of a SKED system is $\$ 3,000$. The projected cost of a basic MicroSKED system is $\$ 300$.

\section{THE INCREASED POWER OF MicroSKED}

MicroSKED has removed some restrictions found in SKED. As indicated earlier, the count of the recording counter and the count of both the response and the $Z$-pulse event counters have been increased. A time-ofday clock has been integrated into MicroSKED. The number of different Z-pulses has been increased from 12 in SKED to 64 in MicroSKED. The greatest increase in power comes to MicroSKED through its variables. SKED allows 24 variables (A through $Z$, excluding $P$ and $T)$. In the basic version of SKED, variables may be used only once. MicroSKED allows 445 variables, which may be used as many times as is desired. MicroSKED has three types of variables: single- $(\mathrm{N})$, double- (B), and triple- (T) precision variables. The symbol for the variable consists of the variable type $(\mathrm{N}, \mathrm{B}$, or $\mathrm{T})$ followed by a number. All variables may be changed on-line via the keyboard.

Single-precision variables may be used to indicate a variable response or $\mathrm{Z}$-pulse (e.g., R N1), a variable stimulus (e.g., ON N2), or a variable state. A transition to $S N 3$ is legal. The transition is to the state indicated by $\mathrm{N} 3$ at the time of the transition. The use of variable states can reduce the size of state tables. A maximum of 255 single-precision variables may be used.

Double-precision variables are used as variable-event counters for responses and Z-pulses. The notation B2 R1 indicates that a transition will occur when the number of $R 1 \mathrm{~s}$ is equal to the value of $B 2$. The value of $B 2$ is determined at the time the state is entered. MicroSKED has a maximum of 127 double-precision variables.

Triple-precision variables are used for time expressions. The maximum number of time variables is 63 .

\section{PACKAGING MicroSKED}

MicroSKED is housed in an $18 \times 8 \times 3 \mathrm{~cm}$ plastic package. It has a 16-character display, which can be used to display the program, the state of the inputs or the outputs, the value of variables or recording counters, or the active state in a given state set. MicroSKED has a 4 by 16 key keyboard, through which programs may be entered or started, variables may be changed, and responses may be entered.

MicroSKED is written for the 6502 microprocessor. The system is interfaced for 124 inputs. Switch bounce is controlled through software. MicroSKED can control up to 124 outputs. Four outputs are available in the basic system. The system has $1 \mathrm{~K}$ of RAM, of which 512 words are available for state tables. An editor, a compiler, and the run-time system are contained on a $4 \mathrm{~K}$ by 8-bit PROM.

The basic MicroSKED can be expanded. An additional 120 outputs may be added in increments of 48 . Each increment adds $2 \mathrm{~cm}$ to the height of the MicroSKED case, and each output can drive $30 \mathrm{~V}$ at $40 \mathrm{~mA}$. A microcassette recorder may be added to MicroSKED. The cassette is integrated into the MicroSKED case. The height of the case is incremented $3 \mathrm{~cm}$ by the cassette. The cassette is capable of recording up to 90,000 characters on one side. The memory size may be incremented by $32 \mathrm{~K}$. This $2-\mathrm{cm}$ addition in height is projected to cost $\$ 200$. A Teletype interface may be added, and a multichannel 8-bit $\mathrm{A} / \mathrm{D}$ and $\mathrm{D} / \mathrm{A}$ converter also can be interfaced to MicroSKED in the future. An optional battery pack may be used to power the minimal system for several hours.

\section{OPERATING MicroSKED}

When power is applied to MicroSKED, the size of usable memory is calculated. MicroSKED then asks for the time of day. When a program is to be compiled, the compile key is depressed. The program is entered one line at a time. Errors are indicated when the end of the line is encountered. The editor allows for error correction. The stop key indicates the end of the compilation. The program is executed by depressing the RTS key. When a program is running, the rightmost 60 keys may be used as responses. The leftmost four keys are system commands. The stop key will halt the execution of the program and clear the interface. The display key will 
cause the specified recording counters, variables, the active state in a state set or the condition of the inputs or outputs to be displayed. The keyboard may not be used to input responses when the display routine is active, since variables may be changed by the keyboard. In the expanded MicroSKED, there are commands to input or output to the Teletype or cassette. The use of the keyboard minimizes the computer type operations (Butler \& Grisham, 1977) in MicroSKED.

\section{MicroSKED OR SKED}

Clearly, MicroSKED is not the solution for every experimental problem, but it appears to be the logical choice in undergraduate laboratories where: the experiment is of medium complexity, the data can be transcribed by hand, and the equipment budget is small. MicroSKED may also be used in research that requires the controller to be brought to the subject. Experiments that require large state tables, collect a large amount of data, or need to be performed simultaneously may require the capabilities of SKED.

\section{MicroSKED TODAY AND TOMORROW}

The prototype of MicroSKED has been constructed, and the software is now in the process of being debugged. It is hoped that MicroSKED can be transferred to other 6502-based systems in the foreseeable future, specifically the PET and the Apple. The transfer will require changes in the software. The hardware used by these systems must be standardized.

In the last 15 years, the cost of computer systems has decreased by a factor of 100 . One wonders what the next step will be. Will a microprocessor be optimized for state notation? Will such a chip lead to a $\$ 29.95$ handheld controller? It certainly is possible. The real question is not whether it will occur, but rather, when?

\section{REFERENCE NOTES}

1. Snapper, A. G., Knapp, J. Z., Kushner, H. K., \& Kadden,
R. M. A notation system and computer program for behavioral experiments. Paper presented at the meeting of the Digital Equipment Corporation Users Society (DECUS), New York, June 1967.

2. Snapper, A. G., Stephens, K. R., Cobez, R. I., \& Van Haaren, F. The SKED software system Manual 2: OS/8 and time-share SKED. Kalamazoo, Mich: The SKED Users Group, 1976.

\section{REFERENCES}

Butler, F. E., \& Grisham, M. G. SKED-controlled experimentation in an undergraduate instructional laboratory. Behavior Research Methods \& Instrumentation, 1977, 9, 219-221.

Elsmore, T. F. Time-of-day clocks and SKED: Techniques and applications. Behavior Research Methods \& Instrumentation, 1977, 9, 231-232.

Lewis, M. F., \& Elsmore, T. F. Revision of SKED: Needs and desires. Behavior Research Methods \& Instrumentation, $1973,5,178-179$.

Norman, D. A. The computer in your briefcase. Behavior Research Methods \& Instrumentation, 1973, 5, 83-88.

SNAPPER, A. G. Use of notational system for digital control and recording. Behavior Research Methods \& Instrumentation, 1973, 5, 124-129.

SNAPPER, A. G. Alternative versions of SKED: Current systems and future plans. Behavior Research Methods \& Instrumentation, 1974, 6, 171-173.

SNAPPER, A. G. A new OS/8 SKED. Behavior Research Methods \& Instrumentation, 1975, 7, 233-238.

Snapper, A. G., \& Kadden, R. M. Time-sharing in a small computer based on a behavior notation system. In B. Weiss (Ed.), Digital computers in the behavior laboratory. New York: Appleton-Century-Crofts, 1973.

Stephens, K. R., \& Van HaAren, F. The origins and development of state notation and SKED. Behavior Research Methods \& Instrumentation, 1977, 9, 72-74.

Walker, A., \& SNAPPER, A. G. Improvements to the SKED processor central software system. In DECUS Proceedings, Spring 1971. Maynard, Mass: Digital Equipment Corporation Users Society, 1971.

Wood, R. W., Sette, W. F., \& WEiss, B. Interfacing the experimenter to the computer: Languages for psychologists. American Psychologist, 1975, 30, 230-238.

\section{NOTES}

1. PDP-8 is a registered trademark of Digital Equipment Corporation, Maynard, Massachusetts.

2. SKED is a registered trademark of State Systems, Inc., P.O. Box 2215, Kalamazoo, Michigan 49003. 